\title{
Pro brain natriuretic peptide (BNP) hormone and tissue Doppler abnormalities in patients with homozygous sickle cell disease in Bahrain: echocardiographic study
}

\author{
Taysir S Garadah $^{1,2_{*}}$, Adla B Hassan ${ }^{1,2}$, Ahmed A Jaradat ${ }^{2}$, Reginald P Sequeira ${ }^{2}$, Abdulla Alajmi ${ }^{1}$ \\ ${ }^{1}$ Salmaniya Medical Complex, Ministry of Health, Manama, Kingdom of Bahrain \\ ${ }^{2}$ Colleges of Medicine and Medical Sciences, Arabian Gulf University, Manama, Kingdom of Bahrain \\ *Corresponding authorE-mail: garadaht@hotmail.com
}

\begin{abstract}
Background: Pulse Doppler echocardiography has a diagnostic value in right and left ventricular function in patients with homozygous sickle cell disease (SCD), however the role of the tissue Doppler is unclear.

Aim: To evaluate the diagnostic role of tissue Doppler in the assessment of right ventricle (RV) and left ventricular function in adult patients with SCD. And to study the prevalence of pulmonary hypertension (PAH) in patients with SCD using the tricuspid valve velocity on echocardiogram.

Method: Seventy patients with homozygous SSD were compared with healthy control. Every patient had clinical assessment, had pulsed and tissue Doppler evaluation, in addition to assessing serum level of hemoglobin, ferritin and pro Brain Natriuretic Peptide (BNP). The mean difference between the two groups for tissue Doppler and biometric variables was assessed.

Results: Seventy patients had SCD (mean age 28 years, 14-40) and $54(77 \%)$ were males. The age and gender proportions were similar in both groups. Patients with SCD compared with the control had significantly low diastolic pressure, lower hemoglobin level, but high serum ferritin and pro BNP hormone. Furthermore, there was a significant increase in the diameter of left atrium, higher left ventricle mass index, and higher right ventricle diameter and wall thickness.

The left ventricle ejection fraction percentage was similar between both groups, but SCD had significantly higher right ventricle tricuspid annular plane systolic excursion (TAPSE) of $1.42 \pm 0.21$ vs. $1.11 \pm 0.23 \mathrm{~cm}(\mathrm{P}=0.02)$. The RV pulsed Doppler data showed restrictive filling pattern with significantly higher $\mathrm{E}$ wave, high E/A ratio and short Deceleration time ; likewise, the upper pulmonary vein systolic/diastolic velocity was significantly lower $1.5 \pm 0.12$ vs. $2.4 \pm 0.11 \mathrm{~cm}(\mathrm{p}=0.002)$.

The tissue Doppler of lateral annulus of tricuspid valve and the septum mitral annulus in SCD patients showed a significant lower S wave, higher E/E- ratio and lower A wave.

The incidence of pulmonary hypertension in SCD patients via tricuspid valve regurgitation (TVR) velocity of $>2.6 \mathrm{~m} / \mathrm{s}$ was $22 \%$. There was a positive correlation between serum level of ferritin, pro BNP and tricuspid valve regurgitation velocity ( $\mathrm{r}=0.35)$ and $(\mathrm{r}=0.43) \mathrm{re}-$ spectively.

Conclusion: Adult patients with SCD had significant right ventricular dilation and increase wall thickness. The LV systolic function is normal but with RV systolic and diastolic dysfunction that was suggestive of restrictive pattern. The incidence of pulmonary hypertension in SCD was $22 \%$ with positive correlation between serum level of ferritin, pro BNP and the development of pulmonary hypertension
\end{abstract}

Keywords: Sickle Cell Anemia, Tissue Doppler, Bahrain.

\section{Introduction}

Sickle cell disease (SCD) is a hereditary hemolytic anemia characterized by the synthesis of hemoglobin S (HbSS). In its homozygous form, sickle cell disease (HbSS) results from the inherence of two sickle cell genes (Bunn et al. 1997).

SCD is characterized by recurrent episodes of hemolytic anemia, vasoocclusive crises with the entrapment of red blood corpuscle in the microvasculature system causing hypo-perfusion infarction in many organ systems leading to multiorgan dysfunction (Platt et al. 1994).

The term sickle cell disease is applied because the inherited abnormality causes a pathological condition that can lead to death and severe complications. Sickle-cell disease occurs more commonly among people whose ancestors lived in tropical and sub-tropical sub-Saharan regions where malaria is or was common. The incidence of SCD in the Arabian Peninsula is in the range of $1.2 \%$ to $2.6 \%$ (Alhamdan, Nasserullah 2003).

Cardiac manifestation of homozygous SCD patient vary and depends on the methods of evaluation and the populations in the study as it seems there are different clinical manifestations of SCD according to patients' ethnicity origin and geographical distribution (Elhazmi 1996, Pearson 1999).

In children with homozygous SCD, the earliest marker of cardiac involvement is diastolic dysfunction followed in adulthood by cardiomegaly and pulmonary hypertension with or without heart failure (Batra 2002, Zilberman2007). 
Pulse Doppler echocardiography is widely used to assess noninvasively the mitral and tricuspid flow for the assessment of diastolic function (Bahl1992, Lindqvist 2009).

The LV diastolic filling pattern on pulsed Doppler has been classified into normal, restrictive and abnormal relaxation pattern on the basis of the relationship between the early filling $\mathrm{E}$ wave and the late filling A wave on Tran's mitral diastolic filling velocity (Choong1987). The pattern of abnormal relaxation pattern had low early filling wave (E) and high atrial wave (A) with E/A ratio $<1$ with high Deceleration Time (DT) of E wave and the constrictive pattern had a high $\mathrm{E}$ wave, diminished or absent $\mathrm{A}$ wave with E/A ratio > 2 and shortened DT of $<160 \mathrm{msec}$ (Moyssakis 2005, Nishimura 1993).

The NT-Pro B-type natriuretic peptide (pro BNP) is a hormone released in response to stretch of myocardial cell. The prognostic value of pro BNP has been demonstrated in several cardiovascular disorders (Ghaderian 2012, Naqvi 2001). The level of pro BNP has been shown to correlate with the severity of pulmonary hypertension and right ventricle dysfunction (Ghaderian 2012). The serum stable and the easily assayed NT-pro BNP have been shown useful in the stratification of pulmonary hypertension (Ommen 2000).

Pulsed Doppler of pulmonary venous velocities (Moyssakis 2005) and Tissue Doppler of mitral and tricuspid annulus were used to assess the systolic and diastolic function of both sides (Ghaderian 2012, Naqvi 2001, Ommen 2000).

\subsection{Aim of the study}

- To evaluate the value of pro-BNP hormone and tissue Doppler indexes in the assessment of diastolic function of RV and LV in adult patients with sickle cell disease.

- To study the prevalence of pulmonary hypertension through measurement of the tricuspid valve regurgitation velocity on continuous wave Doppler.

\section{Material and methods}

\subsection{Study population}

Seventy adolescent and young adult (14-40 year) patients with sickle cell disease (SCD) were enrolled in the study. Patient selection was consecutive with patients attending the hematology clinic in Salmaniya Medical Complex (SMC). SMC is the main government hospital in Bahrain with a catchment area of 900,000. Those patients were compared with 70 healthy patients referred to cardiology OPD for echocardiographic evaluation.

Inclusion criteria were diagnosis of sickle cell disease SCD with homozygous haemoglobin $\mathrm{S}$ (HbSS) made by solubility screening test for sickling and haemoglobin electrophoresis. All patients gave an informed consent and the study protocol was approved by the institutional committee.

Patients with SCD were excluded if they had a history of recent blood transfusion within three weeks, had hemoglobinopathy other than SCD, a history of rheumatic heart disease, adult congenital heart disease, hypertrophic cardiomyopathy, or advanced renal or hepatic failure. All patients had full history and were examined clinically for blood pressure and pulse, presence of heart murmur or crackles, raised jugular venous pulse, S3 gallop, and ankle oedema. Each patient gave a blood sample for the serum level of pro BNP, haemoglobin (HB) and serum ferritin.

\subsection{Echocardiographic evaluation}

Comprehensive echocardiographic pulsed Doppler and tissue Doppler evaluation was performed by Hewlett-Packard e 33 echo machine, using $2.5 \mathrm{MHz}$ transducer by the same cardiologist.

The measurement of M mode, 2D, pulsed and tissue Doppler was performed by two technicians unaware of the subjects' clinical status and according to the American Society of Echocardiography guidelines. The LV ejection fraction (EF \%) was measured using the biplane Simpson methods (Lang 2005).

The M-mode guided echo was used to measure the systolic and end diastolic diameter of LV cavity as well as the septum and posterior wall. The LV mass index was calculated according to the formula described by Devereux et al (Devereux1986).

Right ventricle diastolic diameter and thickness of the free wall were measured in the apical view; RV systolic function was evaluated from the tricuspid annular plane systolic excursion (TAPSE) (Metivier 2000).

Using pulse Doppler for mitral and tricuspid valve in the apical view with the sample volume at the tip of the leaflet in apical view, the following parameters were measured: the early peak velocity (E wave) and the late atrial contraction wave (A wave), $\mathrm{E} / \mathrm{A}$ ratio and deceleration time of $\mathrm{E}$ wave (DT). The calculation of the pulse and tissue Doppler waves was made as the mean of three beats at end of inspiration and three at the end of expiration. The flow velocity of the upper pulmonary veins in the apical view as recorded for systolic and diastolic forward flow velocity ratio (S/D) was determined.

The tissue Doppler of the lateral tricuspid annulus and the septal mitral annulus was obtained for the systolic velocity (S), the early filling velocity $\left(\mathrm{E}^{-}\right)$and late diastolic velocity (A-). All data was taken in the apical four chamber view

\subsection{Statistical analysis}

Data were entered and analyzed using the Statistical Package of Social Sciences (SPSS) version 20. Data are presented as mean \pm SD. Student-test was used to analyze the differences between the mean variables of $M$ mode for septal wall thickness of LV and RV cavity and wall thickness and LV mass index in the two groups as well as DT of E wave and S wave, A wave on tissue Doppler, E/A ratio and $\mathrm{E} / \mathrm{E}$ - ratio.

Pearson correlation coefficient was used to measure the linear relationship between serum ferritin and pro BNP and tricuspid valve velocity on echocardiogram. All reported p-values are two tailed and $\mathrm{p}$-value was regarded as significant at level of $<0.05$.

\section{Results}

There were 70 patients with sickle cell disease with mean age of 28 years (range 14-40), with 54 male (77\%). Table 1 shows the clinical characteristics of the study and the control group.

Patients with SCD compared with the control group had no difference in the age, gender, and systolic blood pressure. But SCD patients compared with norm had significantly low diastolic blood pressure and haemoglobin level but with higher heart rate. There was significant high level of ferritin and pro BNP hormone in SCD patients. Table 2 showed the measurements of M mode and 2D echocardiographic values of right and left ventricle.

Patients with SCD compared with the control had a significant increment in the diameter of left atrium, left ventricle mass index, and right ventricle diameter and wall thickness. There were no significant differences observed between the two groups for the left ventricle ejection fraction percentage, the LV end systolic and end diastolic dimensions but TAPSE was significantly higher indicating right ventricle systolic dysfunction.

Table 3 shows the Pulsed Doppler and tissue Doppler measurements for diastolic filling velocity in both ventricles, the tissue Doppler of the tricuspid lateral annulus, septal mitral annulus as well as the pulmonary vein systolic/diastolic ratio.

SCD patients compared with control had a significantly higher LV E/A ratio, lower A wave velocity and shorter deceleration time of E wave. Also, the right ventricle in SCD patients showed significantly lower A wave velocity and DT was shorter with higher E/A ratio.

The LV tissue Doppler in SCD compared with control showed higher E/E- ratio of $8.9 \pm 1.1$ vs. $6.7 \pm 1.6,(\mathrm{P}=0.03)$ and reduced $\mathrm{S}$ wave of $7.8 \pm 1.8$ vs. $10 \pm 1.2$, ( $\mathrm{p}=0.01)$. In RV the tissue Doppler of 
the lateral annulus of tricuspid valve showed significantly shorter $\mathrm{S}$ wave velocity of $6.7 \pm 1.7$ vs. $1.3 \pm 1.9,(\mathrm{p}=0.01)$, higher $\mathrm{E} / \mathrm{E}$ ratio of $10.2 \pm 1.2$ vs. $7.2 \pm 1.3, p=0.04$ and lower $A$ - wave $5.3 \pm 1.6$ vs. 7.2 $\pm 1.2,(\mathrm{P}=0.02)$. Right upper pulmonary vein systolic /diastolic velocity was significantly lower of $1.5 \pm 0.12$ vs. $2.4 \pm$ $0.11,(\mathrm{p}=0.002)$.

The tricuspid valve velocity showed significant higher velocity in the sickle cell Disease patients of $2.9 \pm 0.14$ vs. $1.7 \pm 0.09, p=0.004$ indicating higher pulmonary artery pressure with calculated right ventricle systolic pressure of 38.64 vs. $16.56 \mathrm{mmHg}$.

Out of the 70 patients with SCD, there were $15(22 \%)$ patients with TVR of $>2.6 \mathrm{~m} / \mathrm{s}$ on continuous wave velocity, three $(4 \%)$ of them had TVR $>3 \mathrm{~m} / \mathrm{s}$ and 65 patients had TVR $<2.6 \mathrm{~m} / \mathrm{s}$. There was positive correlation noted between serum level of ferritin and tricuspid valve velocity of ( $\mathrm{r}=0.35)$. There were 28 out of $70(40 \%)$ patients with SCD who were consuming hydroxyurea medication.

\section{Discussion}

In patients with SCD there was higher heart rate and lower Diastolic blood pressure which is in agreement with other studies where Chronic haemolytic anaemia is accompanied by a state of hyperkinetic circulation and tachycardia (Metivier, F 2000), and reduced peripheral resistance is found with an increase of volume chambers with hypertrophy (Assopoos 2004).

In this study, patients with sickle cell disease had dilation of left atrium and right ventricle compared with the control. Moreover, they had greater left ventricle mass index and thicker RV wall. The systolic function of left systolic ventricle was preserved with no difference between LVEF percent compared with control However RV systolic function as assessed by TAPSE showed significant dysfunction relative to control. It is possible that these parameters of systolic LVEF\% are insensitive due to its loaddependent relationship. It has been observed that patients with SCD had higher preload and lower after-load (Mandinov 1997) which cause higher diastolic filling and shorter DT of E which was observed also in our patients. The RV dysfunction in this study may be due to lung involvement with predominant vasoocclusive effect and smaller RV mass than the left ventricle, resulting in a faster functional derangement.

The diastolic filling pattern for both ventricles was suggestive of restrictive pattern with a significantly high $\mathrm{E}$ wave with shortened deceleration time. This is consistent with one report (Appleton 1987) where preload increment is associated with increase of early filling and shortened deceleration time. In two separate studies the diastolic pattern was mainly of abnormal relaxation pattern (Moyssakis 2005, Braden 1996) but the study population in both was patients with combined SCD and thalassemia.

The tissue Doppler of both tricuspid lateral annulus and septal mitral annulus showed increment of E/E-ratio indicating higher $\mathrm{RV}$ and LV end diastolic pressure with the reduction of $\mathrm{S}$ wave. The tissue Doppler findings in this study are different compared with two studies, whereby one showed similar results between SCD patients and the norm (Akgul 2006) while the other showed that patients with SCD had higher tissue Doppler A- with higher E/E- (Abdul-Mohsen 2012).

The pulmonary vein systolic/diastolic velocity (S/D) ratio was significantly lower in patients with SCD. This is in agreement with one study where S/D ratio was lower in patients with diastolic filling of restrictive pattern (Choong 1987).

Patients with SCD had a lower acceleration time of $<80 \mathrm{~m} \mathrm{sec}$ that agree with another study suggesting mild degree of pulmonary hypertension in SCD patients (Howard 2012).

There were $15 / 70$ (22\%) patients in the SCD group who had pulmonary hypertension with TR velocity of $>2.6 \mathrm{M} / \mathrm{S}$. The incidence of pulmonary hypertension of $22 \%$ in this study was lower than others where the incidences range between $33-45 \%$ (Platt 1994, Sachdev 2007).

The diastolic function may play a role in the development of pulmonary hypertension. In one study by Sachdev et al. (2007, P. 4) it was observed that diastolic dysfunction and pulmonary hypertension can develop independently in patients with sickle cell anaemia whereby each, alone, contribute to increased mortality, while patients with both risk factors have a poor prognosis.

The pathogenesis of pulmonary hypertension in patients with SCD is multifactorial and may be due to sickling phenomena, vasoocclusive crisis or acute chest syndrome. The repetitive intravascular haemolysis results in the release of haemoglobin that scavenges nitric oxide, which finally leads to acute and chronic pulmonary vasoconstriction (Gladwin 2003, Lin 2001).

The positive correlation between the ferritin, pro-BNP and TR velocity in this study support the notion that iron overload (Lin2001) and dilation of the ventricular chambers are implicated in the pathogenesis of pulmonary hypertension (Aessops 2005).

\section{Limitation of the study}

This study was conducted on adult patients but children and adolescent patients were excluded, which may invite for missing important data in terms of disease process in patients with SCD.

Table 1: Clinical Characteristics of the Study Population (Data Presented as the Mean \pm SD)

\begin{tabular}{llll}
\hline Characteristics & SCD N=70 & Control N=70 & P value \\
\hline Age & $28.52 \pm 9.11$ & $29.74 \pm 8.71$ & 0.64 \\
Male & $54(77 \%)$ & $53(76 \%)$ & 0.76 \\
Heart rate $/ \mathrm{min}$ & $79 \pm 8$ & $71 \pm 4$ & 0.04 \\
$\mathrm{SBP}(\mathrm{mmHg})$ & $128.47 \pm 7.92$ & $124.58 \pm 8.65$ & 0.85 \\
DBP $(\mathrm{mmHg})$ & $67.84 \pm 4.55$ & $75.25 \pm 3.88$ & 0.042 \\
Haemoglobin $(\mathrm{g} / \mathrm{L})$ & $9.3 \pm 1.2$ & $13.2 \pm 1.5$ & 0.01 \\
Serum ferritin $\mathrm{ng} / \mathrm{ml}$ & $323.25 \pm 78.23$ & $86.12 \pm 16.34$ & 0.01 \\
Serum pro BNP pmol/L & $365.76 \pm 96.34$ & $98.54 \pm 19.58$ & 0.01 \\
\hline
\end{tabular}

Abbreviations: SBP, systolic blood pressure; DBP, diastolic blood pressure; SCD, sickle cell disease; BNP, brain natriuretic peptide.

Table 2: The M Mode and 2-D Echocardiographic Data in the Study Population (Data Presented as the Mean \pm SD)

\begin{tabular}{llll}
\hline & SCD N=70 & Control N=70 & P value \\
\hline LA $(\mathrm{cm})$ & $4.21 \pm 0.87$ & $3.53 \pm 0.67$ & 0.04 \\
LVEDD $(\mathrm{cm})$ & $5.51 \pm 0.32$ & $4.72 \pm 0.35$ & 0.36 \\
LVESD $(\mathrm{cm})$ & $3.63 \pm 0.24$ & $3.12 \pm 0.31$ & 0.65 \\
LV mass index & $105 \pm 10.3$ & $83 \pm 7.1$ & 0.001 \\
RV diameter(cm) & $2.8 \pm 0.42$ & $2.4 \pm 0.31$ & 0.043 \\
RV wall thickness $(\mathrm{mm})$ & $0.31 \pm 0.06$ & $0.28 \pm 0.03$ & 0.024 \\
LVEF $($ percentage $)$ & $58.90 \pm 4.7$ & $61.22 \pm 3.9$ & 0.061 \\
RV TAPSE $(\mathrm{mm})$ & $1.28 \pm 0.21$ & $1.11 \pm 0.23$ & 0.04 \\
\hline
\end{tabular}

Abbreviations: LA, left atrium; LVEDD, left ventricle end diastolic dimension; LVESD, left ventricle end systolic dimension; $\mathrm{EF} \%$, ejection fraction percentage; TAPES, tricuspid annular plane excursions.

Table 3: Pulsed and Tissue Doppler Parameters in the Study Patients, (Data Presented as the Mean \pm SD)

\begin{tabular}{llll}
\hline Parameters & SCD & Control & P value \\
\hline LV E wave (msec) & $85.23 \pm 1.92$ & $62.43 \pm 1.67$ & 0.001 \\
LV A wave (msec) & $46.26 \pm 4.7$ & $56.24 \pm 3.2$ & 0.032 \\
LV E/A & $1.86 \pm 0.01$ & $1.10 \pm 0.03$ & 0.024 \\
LVDT of E wave (msec) & $156.43 \pm 23.5$ & $189.87 \pm 19.5$ & 0.031 \\
RV E wave (cm/s) & $76.65 \pm 1.43$ & $59.34 \pm 1.9$ & 0.04 \\
RV A wave (cm/s) & $40.65 \pm 3.5$ & $49.65 \pm 3.4$ & 0.043 \\
RV E/A & $1.93 \pm 0.03$ & $1.20 \pm 0.02$ & 0.076 \\
RV DT of E wave (msec) & $176.24 \pm 21.4$ & $210.43 \pm 0.24$ & 0.012 \\
RV pulmonic vein S/D & $1.5 \pm 0.12$ & $2.4 \pm 0.11$ & 0.002 \\
PV accT (msec) & $94.24 \pm 11.3$ & $110.14 \pm 14.8$ & 0.041 \\
Tricuspid valve regurgitation & $2.9 \pm 0.14$ & $1.7 \pm 0.09$ & 0.04 \\
velocity (m/s) & $6.7 \pm 1.7$ & $11.3 \pm 1.9$ & 0.01 \\
Tissue Doppler tricuspid S wave & $10.2 \pm 1.2$ & $7.2 \pm 1.3$ & 0.04 \\
TD of tricuspid E/E - ratio & $5.3 \pm 1.6$ & $7.2 \pm 1.2$ & 0.02 \\
TD of tricuspid A - wave & $8.9 \pm 1.1$ & $6.7 \pm 1.6$ & 0.03 \\
TD of mitral E/E- & $7.8 \pm 1.8$ & $10.6 \pm 1.2$ & 0.01 \\
TD of mitral S wave & $4.2 \pm 1.2$ & $6.8 \pm 1.4$ & 0.02 \\
TD of mitral A- wave & & &
\end{tabular}


Abbreviations: SCD, sickle cell disease; LV, left ventricle; RV, right ventricle; E, pulsed Doppler early diastolic filling (E) A, atrial diastolic filling (A); DT deceleration time of E wave; Etissue Doppler E wave (DT); A- tissue Doppler of A wave (A-); $\mathrm{S} / \mathrm{D}$, systolic/diastolic wave ratio; $\mathrm{S}$, systolic wave; acc $\mathrm{T} \mathrm{PV}$, acceleration time of pulmonary valve; TD, tissue Doppler.

\section{References}

[1] Bunn HF (1997) Pathogenesis and treatment of sickle cell disease. (1997) The New England Journal of medicine 337,762-9. doi:10.1056/NEJM199709113371107.

[2] Platt OS, Brambilla DJ, Rosse WF, Milner PF, Castro O, Steinberg $\mathrm{MH}$, et al (1994) Mortality in sickle cell disease. Life expectancy and risk factors for early death. The New England Journal of medicine 330, 1639-44. doi:10.1056/NEJM199406093302303.

[3] Alhamdan NA, Almazrou YY, Alswaidi FM, Choudhry AJ (2007) Premarital screening for thalassemia and sickle cell disease in Saudi Arabia. Genetics in medicine: Official Journal of the American College of Medical Genetics 9, 372-7. doi:10.1097GIM.0b013e318065a9e8.

[4] Nasserullah Z, Alshammari A, Abbas MA, Abu-Khamseen Y, Qadri M, Jafer SA, et al. (2003) Regional experience with newborn screening for sickle cell disease, other hemoglobinopathies and G6PD deficiency. Annals of Saudi medicine 23,354-7.

[5] el-Hazmi MA, Warsy AS, al-Swailem AR, al-Swailem AM (1996) Bahakim HM. Sickle cell gene in the population of Saudi Arabia Hemoglobin 20, 187-98.

[6] Pearson HA (1999) Reply: Sickle cell disease in the Kingdom of Saudi Arabia: East and West. Annals of Saudi medicine 19, 281-2.

[7] Batra AS, Acherman RJ, Wong WY, Wood JC, Chan LS, Ramicone E, et al. (2002) Cardiac abnormalities in children with sickle cell anemia. American Journal of Hematology 70, 306-12. doi:10.1002/ajh.10154.

[8] Zilberman MV, Du W, Das S, Sarnaik SA (2007) Evaluation of left ventricular diastolic function in pediatric sickle cell disease patients. American Journal of hematology 82, 433-8. doi:10.1002/ajh.20866.

[9] Bahl VK, Malhotra OP, Kumar D, Agarwal R, Goswami KC, Bajaj R, et al (1992) Noninvasive assessment of systolic and diastolic left ventricular function in patients with chronic severe anemia: a combined M-mode, two-dimensional, and Doppler echocardiographic study. American Heart Journal 124, 1516-23.

[10]Lindqvist P, Henein MY, Wikstrom G (2009) Right ventricular myocardial velocities and timing estimate pulmonary artery systolic pressure. International Journal of Cardiology137,130-6. doi:10.1016/j.ijcard.2008.06.043.

[11]Choong CY, Herrmann HC, Weyman AE, Fifer MA(1987) Preload dependence of Doppler-derived indexes of left ventricular diastolic function in humans. Journal of the American College of Cardiology $10,800-8$.

[12]Moyssakis I, Tzanetea R, Tsaftaridis P, Rombos I, Papadopoulos DP, Kalotychou V, et al (2005) Systolic and diastolic function in middle aged patients with sickle beta thalassaemia. An echocardiographic study. Postgraduate Medical Journal 81, 711-4. doi:10.1136/pgmj.2004.031096.

[13]Nishimura RA, Schwartz RS, Tajik AJ, Holmes DR, Jr (1993) Noninvasive measurement of rate of left ventricular relaxation by Doppler echocardiography. Validation with simultaneous cardiac catheterization. Circulation 88, 146-55.

[14]Ghaderian M, Keikhaei B, Heidari M, Salehi Z, Azizi Malamiri R (2012). Tissue Doppler echocardiographic findings of left ventricle in children with sickle-cell anemia. The Journal of Tehran Heart Center 7, 106-10.

[15]Naqvi TZ, Neyman G, Broyde A, Mustafa J, Siegel RJ (2001) Comparison of myocardial tissue Doppler with transmitral flow Doppler in left ventricular hypertrophy. Journal of the American Society of Echocardiography: official publication of the American Society of Echocardiography14, 1153-60.

[16]Ommen SR, Nishimura RA, Appleton CP, Miller FA, Oh JK, Redfield MM, et al (2000) Clinical utility of Doppler echocardiography and tissue Doppler imaging in the estimation of left ventricular filling pressures: A comparative simultaneous Doppler-catheterization study. Circulation 102, 1788-94

[17]Lang RM, Bierig M, Devereux RB, Flachskampf FA, Foster E, Pellikka PA, et al (2005) Recommendations for chamber quantification: a report from the American Society of Echocardiography's Guidelines and Standards Committee and the Chamber Quantification Writing Group, developed in conjunction with the European Association of Echocardiography, a branch of the European Society of Cardiology. Journal of the American Society of Echocardiography : official publication of the American Society of Echocardiography 18, 1440-63. doi:10.1016/j.echo.2005.10.005.

[18]Devereux RB, Alonso DR, Lutas EM, Gottlieb GJ, Campo E, Sachs I et a (1986) Echocardiographic assessment of left ventricular hypertrophy: comparison to necropsy findings. The American Journal of Cardiology 57, 450-8.

[19]Gladwin MT, Sachdev V, Jison ML, Shizukuda Y, Plehn JF, Minter $\mathrm{K}$, et al (2004) Pulmonary hypertension as a risk factor for death in patients with sickle cell disease. The New England Journal of Medicine 350, 886-95. doi:10.1056/NEJMoa035477.

[20]Metivier F, Marchais SJ, Guerin AP, Pannier B, London GM (2000) Pathophysiology of anaemia: focus on the heart and blood vessels. Nephrology, dialysis, transplantation : official publication of the European Dialysis and Transplant Association - European Renal Association 15 Suppl 3, 14-8.

[21] Aessopos A, Deftereos S, Farmakis D, Corovesis C, Tassiopoulos S, Tsironi M, et al. (2004) Cardiovascular adaptation to chronic anemia in the elderly: an echocardiographic study. Clinical and investigative medicine Medecine clinique et experimentale 27, 265-73.

[22] Mandinov L, Kaufmann P, Brunner F, Hess OM (1997) [Anemia and heart function]. Praxis 86, 1687-92.

[23]Appleton CP, Hatle LK, Popp RL (1987) Superior vena cava and hepatic vein Doppler echocardiography in healthy adults. Journal of the American College of Cardiology 10: 1032-9.

[24]Braden DS, Covitz W, Milner PF (1996) Cardiovascular function during rest and exercise in patients with sickle-cell anemia and coexisting alpha thalassemia-2. American Journal of hematology52,96-102. 8652(199606)52:2<96:AID-AJH5>3.0.CO;2-0.

[25]Akgul F, Yalcin F, Babayigit C, Seyfeli E, Seydaliyeva T, Gali E (2006) Right ventricular and pulmonary function in sickle cell disease patients with pulmonary hypertension. Pediatric cardiology $27,440-6$ doi:10.1007/s00246-006-1257-8.

[26] Abdul-Mohsen MF (2012) Echocardiographic evaluation of left ventricular diastolic and systolic function in Saudi patients with sickle cell disease. Journal of the Saudi Heart Association24,217-24. doi:10.1016/j.jsha.2012.05.001

[27] Howard LS, Grapsa J, Dawson D, Bellamy M, Chambers JB, Masani ND, et al (2012) Echocardiographic assessment of pulmonary hypertension: standard operating procedure. European respiratory review : Official Journal of the European Respiratory Society21,23948. doi:10.1183/09059180.00003912.

[28] Sachdev V, Machado RF, Shizukuda Y, Rao YN, Sidenko S, Ernst I, et al (2007) Diastolic dysfunction is an independent risk factor for death in patients with sickle cell disease. Journal of the American College of Cardiology 49, 472-9. doi:10.1016/j.jacc.2006.09.038.

[29]Gladwin MT, Schechter AN, Ognibene FP, Coles WA, Reiter CD, Schenke WH, et al (2003) Divergent nitric oxide bioavailability in men and women with sickle cell disease. Circulation 107, 271-8.

[30]Lin G, Macdonald RL, Marton LS, Kowalczuk A, Solenski NJ, Weir BK (2001) Hemoglobin increases endothelin-1 in endothelial cells by decreasing nitric oxide. Biochemical and biophysical research communications 280, 824-30. doi:10.1006/bbrc.2000.4167.

[31]Aessopos A, Farmakis D (2005) Pulmonary hypertension in betathalassemia. Annals of the New York Academy of Sciences 1054, 342-9. doi:10.1196/annals.1345.041. 